\title{
Application of the "Unconscious" of Psychoanalysis in Design
}

\author{
Hongyan $\mathrm{Yu}$ \\ Art Design Department \\ Humanities School \\ Yantai Nanshan University \\ Longkou County, Yantai, Shangdong, China, 265713 \\ e-mail: 178859503@qq.com
}

\author{
Haifeng Dai \\ Art Design Department \\ Humanities School \\ Yantai Nanshan University \\ Longkou County, Yantai, Shangdong, China, 265713 \\ e-mail: 181992039@qq.com
}

\begin{abstract}
The theory of the "unconscious" is one of the key elements of psychoanalysis, which, ever since its appearance, has been spreading rapidly into other fields of social sciences, such as literature, philosophy, art, etc. Mr. Naoto Fukasawa, the Japanese master of design, proposed the concept of "unconscious design" by introducing the "unconscious" into designing. Research and application of the "unconscious" in designing gives the designer a new opportunity to inspire new creations to better gratify customers' requirements.
\end{abstract}

Keywords - the unconscious; collective unconscious; design

\section{THE "UnCONSCIOUS" IN PSYChOANALYSIS}

The unconscious, namely subconscious, refers to the things that one cannot be aware of under normal circumstances, e.g., desires buried deep in the mind and unable to be clearly recognized. According to theories relating to psychoanalysis, human "unconscious" originates from the suppressed "id". This is because the primitive drive of "id" can not be completely accepted by social morality and ethics. The "Id", being suppressed by the "superego" can only be deposited in the back of human minds and becomes subconscious. This is the so called "iceberg theory". If we compare human consciousness to an iceberg, the consciousness above the water is only a very small part of the iceberg, while most of the iceberg hides under the water, greatly influencing the visible part. The part of the iceberg under the water represents the unconscious. Freud thinks that the unconscious is dynamic, which can actively affect human characteristics and behaviors, either intentionally or unintentionally.

While Freud's research concerning the unconscious stops at the individual unconscious level, his most controversial student, Jung, further develops his theory by dividing the unconscious into "individual unconscious" and "collective unconscious". In comparison with Freud, Jung finds more importance in the collective unconscious. The collective unconscious is the unconscious at the very bottom of a person's personality structure, which includes the traits inherited from the behavioral patterns and life experiences of our ancestors. This is a possibility, an obscure memory that accumulates incessantly in the human brain and could be awakened and activated under certain circumstances. Jung thinks that the primitive images deposited in the "collective unconscious" are an important source for artistic creation. He thinks that ideas artists are most eager to express are actually ideas with far-reaching influences, which one may be unaware of and may extend subconsciously. They are scattered throughout the collective unconscious. Artists serve as the soil where seeds of the unconscious can take roots and thrive. They use creation and recreation to present the most profound and general "consciousness" in the form of art.

Therefore, we can see that the unconscious is an important source of artistic creation. However, design, being use-oriented, seems unrelated to the unconscious because it is more rational than artistic creation. This is not true. Especially in the present when design continues its evolution from the modernist phase, which highlights economy, simplicity and utility, to the internationalist and functionalist phase, which attach unjust importance to utility and rationality at the expense of humanistic concern, to the postmodernist phase, which gives weight to humanized and emotionalized design. Thus, the unconscious finds its stage in design. Exploration and application of the unconscious of the designer and his subjects proposes a new way of design.

\section{THE UnCONSCIOUS AND DESIGN}

"Unconscious" does not mean a lack of consciousness. It expresses, rather, the situation where people feel that they want something but are unable to recognize and identify what it is they really want. The unconscious design focuses on human unconsciousness and tries to use design to help people accomplish some behavior in a way that is difficult to observe. The research and application of the unconscious gives not only a new opportunity for designers to evolve their design and creation, but also a new way to better gratify the customers' needs.

Deep within every one's mind, there is a deposit of precious life experiences and emotional memories. Unconscious design, establishing itself on this fact, makes good use of these experiences and memories to motivate every emotional fiber of the user. It is more accurate to speak of design as emotional exchange between the designer and customer than as a creative process. Though the emotional exchange is intangible, it is deeply motivated. This is the 
essence of unconscious design. For example, the Child-funsoaked Girotondo project by two genius designers of Guido-Venturini and Stefano-Giovannoni from Alessi, an Italian company, manifests the deep-digging and presentation of the unconscious. The Girotondo project developed from a kind of fruit tray to over 70 kinds of products that fall under 5 classifications: kitchen wares, sanitary products, stationery, ornaments and desktop products. On each one of the products there is always an icon of a boy. Girotondo series products, first emerging on the market in 1989, was favorably acclaimed and made extraordinarily good sales record. Why do people have such an intense interest in a simple paper cutout cartoon image of a boy? The reason is simple. This image resonates with their unconscious intentionally or unintentionally. In Italy, Girotondo is a very common word; nearly every Italian has memories related with this word. The word Girotondo stands for child rhyme, child play, kindergarten and many other things related with the children. Girotondo is a very famous rhyme for the children, which accompanies nearly every Italian in their adolescence. Secondly, Girotondo is also a traditional game for Italian Children and almost every Italian played this game in their youth. Thirdly, most kindergartens in Italy are named Girotondo, making it safe to say that nearly all Italian grow up in Girontondo. Furthermore, in kindergarten handicraft classes, every child learns to cut the figure of a boy. Thus we can see that Girontondo becomes a symbol that reminds every Italian of childhood memories and is deposited securely deep in their minds. As Giovannoni said, "Girontondo is a visualized icon, it is always a part of our culture, which is hidden by design". When Girotondo designs appeared before customers' eyes, happy memories from their childhood are brought up naturally in the mind which, evoking feelings of warmth and closeness. Thus the exchange and communication between products and humans are accomplished.

Alberto Alessi, manager of Alessi, an Italian company, once said, "deep in every one's mind, there is need for innocent, naive and simple things that can bring happiness and security." However, most of the above-mentioned things lay hidden in our unconscious. In order to dig these things up, we need designers to present designs that trigger these dormant, déjà vu aspects and create a resonance with the costumer that acts as a wordless hint to behave in a certain way. "Unconscious design is a way to explore solutions; it contends that designing memory of a behavior is different from designing a shape."[1] This design concept means to integrate people and things organically into the environment under the precondition of not diverting the users' attention as well as making them feel like an indispensable part of that environment. The users' feeling of comfort and closeness come seemingly from nothing, as all feelings are naturally inspired and are not forced by external factors.

Here is another example from the "Most Successful Design Contest in 2013". During this contest, the Aurora Design Center won favors from a panel of international judges and was awarded with the "the Most Successful Design" for its rocking horse stool. The rocking horse stool looks like the commonplace rocking horses in every fun fair, but in essence, it is a tradition-subverting and humanitiesoriented design typical of exploration and application of using the collective unconscious in design. What was original about the Aurora Design Center's Rocking Horse Series design?

Rocking horses are a part of most children's lives, and, whether they own one or not, are associated with happy and beautiful memories that remain in the subconscious. The Aurora Design Center brought this memory back into reality by threading the memory of the child's life into the designing and shaping of office chairs into fun-infused rocking horses, which is easily importable and offers dynamic elements to a tense and solemn offices.

The Aurora Design Center's rocking horse stool overthrows traditional concepts concerning office chairs and provides a successful nostalgia-featured model for renovating and designing office furniture. A heart-warming chair, which can be used in different offices in a flexible way, can alleviate tenseness and dullness in offices. Mr. Li Wangsheng, Chief Design Director of Aurora Center said, "the technique of using curved wood plank making rocking horse stools will make the main structure simpler and more fashionable. The seat cushion made of molding foam guarantees comfort. Net bags installed in the hollow part of the main structure can hold books, office articles.[2] Colorfulness and fashionable appearance help nourish light and fun atmosphere in the office. People swinging their body on the rocking horse stool will also feel the horse rocking to and fro in accompaniment of the stool rider, where practical utility merge with humanistic care in a perfect way. Ever since its entrance into market, rocking horse stools were rapidly popularized among office workers born in the 1980s. These stools not only satisfy their emotional needs, but also earn the company a reputation as a young and creative brand. From this we can see that a successful design needs to not only highlight its feature in shape, material, texture, color and other physical factors, but also follow closely the consumers' needs, which is the key to the success. The unconscious is usually what even the consumer himself can not enunciate but plays an important role in the subconscious.

\section{SOURCE OF THE UnCONSCIOUS IN DESIGN}

Firstly, close observation will help you integrate the design with life and experience. Practice leads to true knowledge. There is a great amount of "unconsciousness", whether individual or collective, in daily life. And there is also a great deal of unconscious requirements, which in most cases one can not be aware of, let alone clearly expound on. Therefore, designers must exert their special designing philosophy to catch this fleeting unconsciousness by close observation and direct experience of life, transforming them into design inspirations and trying to meet the unconscious needs of the subjects.

Jung thinks that collective unconscious generally exists. Life is permeated with collective unconsciousness. The collective unconscious originates from varied prototypes. There are as many typical situations as prototypes. Therefore, the collective unconscious is a universal and collective 
psychological activity that goes beyond the bounds of individuals, nations and races, transcends personal postnatal life experience and is independent of personal experience."[3] Like Gaetano Pesco, widely nicknamed the Italian Design Maniac, who came up with the UP series design in 1969, which was popularly recognized as a milestone in the reform of Italian furniture design. Especially, the UP5/UP6 design became the signatory symbols of Italian design for its intense visual impact and personified control (the shape was inspired by a woman's body). The sofa takes its the shape nearly from a woman's contour, and connects with a ball-shaped foot mat, whose peculiar and original appearance earned it the nickname of "pregnant mom" and "mom's embrace", etc. In most people's memory, the coziest thing is to sit in their mother's embrace. This comfort and security is a kind of collective unconsciousness deeply buried in people's minds. Taking advantage of the warm nostalgia deep in the mind and constructing a bridge between the design and the subconscious creates precious intangible communication. Works thus designed are no longer cold and emotionless ornaments in the consumers' eyes but rather objects capable of evoking an almost déjà vu level of closeness.

Secondly, deep understanding of the culture, traditions and customs of different regions will help nourish creative inspiration. Classical tradition and folk culture, even classic works in daily life, all survived throughout history and accumulated in a plentiful collective unconscious. They represent the typical inheritance of the collective unconscious. Inspirations of artistic creation originate from designers' personal experience as well as culture, tradition and customs passed down through generations from human ancestors. Take for example Jin Daiqiang, Chen Youjian, et al, whose design become a classic mainly for their blending of the essence of traditional Chinese culture with modern design. Jin Daiqiang asserts that both designers and artists must find the origin of their creation in their own culture and, only by doing this, can their design lives a longer life. Therefore, he accepts western avant-guard art concepts while also trying his best to understand Chinese Confucian, Taoist and Buddhist thoughts and infuse some of their essence into creation and design. For example, the silverware "hand in hand" he designed for commemorating the return of Hong Kong in 1997 gave a full presentation of the Confucian philosophy of "home, country and the world" through the image of a mother and son holding hands. In the postcard designed in 1989 for the "Dancing Festival of International Dancing University", he uses the allusion of "Zhuangtsu dreamt of transforming into a butterfly" to present the Taoist philosophy of unification. Another example is that Chen Youjian always pursues "harmony" as the aim of his design. "Harmony" is important in the treaditional Chinese heritage and philosophy. Chen Youjian draws from many traditional techniques and concepts from Chinese painting and calligraphy and integrates them with modern plane design in an organic way to produce overwhelmingly successful artworks. He does not force these traditional Chinese elements into his design. Instead, he does careful analysis and uses modern techniques to present these Chinese elements in a moderate and spontaneous way so as to achieve the truthful integration of the traditional and the modern, bringing artistic design to a new level of quaintness and extraordinary refinery. Design could not proceed without innovation. This innovation also includes that of classics. Successful designers tap into the cultural inheritance while also breaking away from classics and traditions. These classics and traditions are collective unconscious that we need to explore.

In the current world, when material products are extremely rich and plentiful, a design faces strong challenge in its development. Consumers not only have simple demand on the usage but also have spiritual requirements about the products. Application of the unconscious in design will help to gratify these spiritual requirements. However, designers must notice that "unconscious" is not omnipotent. It is one way but not the only way to generate creation and innovation. After all, the unconscious is emotional and irrational. It is not only the unconscious that can develop into an unconscious design. Designers must make their choices between the conscious and the unconscious of the consumers instead of catering blindly to their demands; only by doing this can designers exert the positive power of the unconscious in design.

\section{REFERENCES}

[1] Yin Huan, Guo Ge. A Tentative Analysis on Application of "Unconscious Design" in Household Products Design [A]. Garden [J] Kunming: Yunan People's Press, May, 2012, the 9th Edition, P40.

[2] Li Wangsheng. Deconstruct Rocking Horse Stools by Aurora Design Center: the Trump Subverting Office Furniture Design. http://www.baohaosi.net/index.php?a=show\&c=content\&id $=492$

[3] Jung. Theory and Practice of Psychoanalysis [M]. Cheng Qiong, Wang Zuohong Trans. Beijing: Shanlian Press, 1991. 